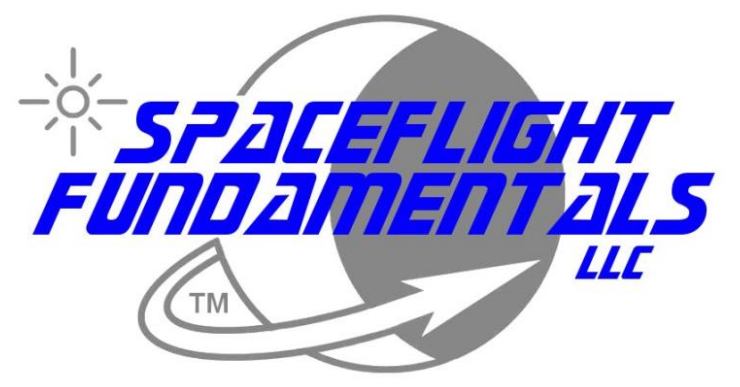

\title{
Spaceflight Academy for CESA District \#7
}

\author{
Bradley J. Staats, President \\ Spaceflight Fundamentals, LLC \\ Greenville, Wisconsin
}

\begin{abstract}
Synopsis: Spaceflight Academy for Cooperative Educational Service Agency (CESA) District \#7 was a teacher workshop ${ }^{1}$ that focused on the history, math, science, and technology of spaceflight. This workshop offered a unique approach to teaching by incorporating "real world" applications into the classroom.
\end{abstract}

Goals and Project Value: Spaceflight Academy for CESA District \#7 was a one-day workshop that focused on STEM (Science, Technology, Engineering, and Math) related topics for spaceflight. The course offered a unique approach to teaching and answering the age old question "Why do I have to learn this?" by elegantly incorporating "real world" applications into the classroom. Instructors experienced a unique approach to teaching math, science, and technology standards by tackling real world issues in inspiring classroom experiences. Spaceflight Academy for CESA District \#7 utilized award-winning approaches to advance an educator's knowledge base by employing a fun, hands-on approach to learning.

For this year's workshop, instructors in the Cooperative Educational Service Agency \#7 district were the target audience. The workshop was setup to provide 20 instructors with a full day of instruction and over $\$ 100$ per person in materials and resources to take back to their respective classrooms. A lunch was also provided to all participants. After advertising extensively for this 3-12 workshop, a total of 25 instructors pre-registered for it. Forty eight percent were middle level instructors while the remaining fifty two percent were high school instructors.

Due to the variety of teaching levels present for this workshop, the workshop was broken into three basic segment/components - elementary/middle and high school level topics. The workshop was co-facilitated. The AM sessions were devoted to elementary/middle level discussions while the PM session was devoted to high school topics. During these sessions the following topics/activities were covered: perception / paradigm shifts; center of gravity; Bernoulli implications; Newton's universal law of gravitation; various orbital shapes (conic sections); circular orbits; geosynchrous orbits; elliptical orbits; spaceflight mathematics; history of human space exploration; and technologies of space exploration.

\footnotetext{
${ }^{1}$ The main financial support for this workshop was provided by the Wisconsin Space Grant Consortium. Additional support was provided by the following sponsors: Spaceflight Fundamentals, LLC; Science Kit \& Boreal Labs; and the Green Bay Area School District.
} 
Evaluation Results: At the conclusion of this workshop, the following questions were asked on an evaluation form. The results, of this evaluation, are based on a 100-point scoring system with $100 \%=$ strongly agreeing with the provided statement, $80 \%=$ agreeing with the statement, and so on.

1. My exposure to this project has increased my knowledge/understanding in space, aerospace, space-related science, design, and technology. [Score $=\mathbf{9 1 \%}$.]

2. Student exposure to this project could increase an interest in space, aerospace, spacerelated science, design, and technology. [Score $=\mathbf{9 4 \%}$.]

3. The project has self-sustaining/replicable qualities due to the fact that the participants are trained and supplied with the basic materials to go out and duplicate in their classrooms the work that was incorporated in this workshop. [Score $=\mathbf{9 7 \%}$.]

4. The project meets the goal of Teacher Training which is defined as successfully educating, training, and exciting teachers about the math, science, technology, and history pertaining to spaceflight. [Score $=\mathbf{9 3 \%}$.]

5. The instructors were knowledgeable about the subject matter that was being taught. [Score $=\mathbf{1 0 0 \%}$.]

6. The workshop was well organized. [Score $=\mathbf{9 7 \%}$.]

7. The instructors' presentation style was well suited for the audience in attendance. [Score $=96 \%$.]

8. I am pleased with the information and materials that I received as part of this workshop. [Score $=99 \%$. $]$

9. What is the total number of students that you teach per day? [*Based on the number of instructors present and their teaching assignments, a total of $1 \mathbf{1 7 3 5}$ students will be positively impacted by this workshop.]

10. How do you plan to implement this material into your classroom curriculum? [*The following are highlights of responses to this question]

"I want to work it into current labs that I currently use. It also gives me some grabbers to get the student's thinking."

"Use the activities/projects as they relate to my curriculum and the core standards."

"I hope to use these activities in my room with kids to get them excited about space."

"I like the "make and take' projects. I will be implementing many of these at the beginning of the year when teaching 'observation and problem solving' skills."

"I enjoyed the challenge activities. I would like to use some of the activities at the beginning of the year as team building/ice breaking activities."

I will incorporate this as a "new unit in physics".

"I will use the Bernoulli materials in my physics and microgravity." 
I will implement the materials into "all classes".

"I plan on using the software to integrate technology into the science curriculum. I will use many of the hands-on activities... all mainly in earth science courses."

"I will use the software program in my astronomy classes and the rocket launcher in physics."

"I will add it to my astronomy unit."

11. Please express any additional comments regarding the workshop and/or instructors. [*The following are highlights of responses to this question]

"Extremely well done. Practical and easy to duplicate. Great presentation methodology."

"It is so nice to leave with materials I can use immediately in my classroom! Also learning new perspectives to share."

"I am so glad I attended, as this is one of the most useful workshops I've attended."

"This was a great workshop. I enjoyed the pace."

"Wonderful - Very useful information."

Presentations were "excellent for all levels".

"Software is very cool. Students will like to do this."

"This was a fantastic variety of projects covering very relevant topics in science."

"Nicely paced and kept busy with hands-on activities."

Evaluation Analysis: Based upon the positive evaluations and comments of these grades 3-12 teachers, there should be a definite increase for interest in space, aerospace, space-related science, design, technology, and its potential benefits for their students in CESA District \#7. Invariably, based on our evaluations, this project should allow secondary (pre-college) students the opportunity to increase their interest, recruitment, experience and training in the pursuit of space or aerospace related science, design, or technology in CESA District \#7.

The project has self-sustaining/replicable qualities due to the fact that the instructors that were trained were supplied the basic materials to go out and duplicate the work that we incorporated in our workshop. The goal is for teachers to go back to their classroom and replicate this work to their students - the "multiplier effect" is then engaged. Through this effect, teachers are able to provide their students with exposure to this exciting curricular approach. For the 2012-2013 school year, 1735 students will have the opportunity to be exposed to this worthwhile curriculum. Based upon the amount of grant money received from the Wisconsin Space Grant Consortium (WSGC) and the number of students each registered instructor has, it only cost WSGC an average of $\$ 1.72$ per student to run this workshop - this is an amazing investment!

The goal for this program is to have it ultimately offered throughout the state. Based upon the workshop's evaluations, the project certainly met this year's specific goal of Teacher Training. The whole purpose of the project is to educate, train, and excite teachers about the math, science, technology, and history pertaining to spaceflight - This workshop definitely and successfully accomplished this feat. 
Alignment with the Science Mission Directorate (SMD): Earth Science, Heliophysics, Planetary Science, and Astrophysics. The scientific investigation of the Earth, Moon, Mars and beyond with emphasis on understanding the history of the solar system, searching for evidence of habitats for life on Mars, and preparing for future human exploration.

This workshop exposed and prepared teachers for our next generation of scientists to aerospace related fields. As we prepare for future space exploration, we will need many new scientists and engineers to accomplish this endeavor. Our workshop's goal was to train teachers who in turn will train future scientists and engineers.

Human Exploration and Operations (HEO): The HEO mission Directorate provides the Agency with leadership and management of NASA space operations related to human exploration in and beyond low-Earth orbit.

The workshop had a focus on past and future exploration system development needs, human space flight capabilities, and advanced exploration systems.

Educational Standards: The National Research Council's (NRC) Science Education Standards were addressed throughout the workshop. Special emphasis was put on the following Standards areas: The Teaching Standards: Guiding and Facilitating Learning \& Building Learning Communities; The Professional Development Standards: Learning Science Content, Learning To Teach Science, \& Learning To Learn; and The Content Standards: Scientific Inquiry, Technological Design, \& Science and Technology.

Participants: The workshop was limited to 20 science and/or math instructors. It was made available on a first come, first serve basis. Spaceflight Fundamentals, LLC fully complies with the Americans with Disabilities Act of 1990 (ADA), Section 504 of the Rehabilitation Act of 1973, and its amendments, all of which prohibit discrimination on the basis of disability in the admission, access to, or participation in programs or activities.

Location of Project: The workshop was advertised to science/math (Grades 3-12) teachers in the CESA \#7 district (Green Bay area). The workshop was located at the Lombardi Middle School, 1520 South Point Road, Green Bay, WI. We coordinated the workshop advertisement with school districts in the Green Bay / CESA \#7 area. The target audience was science / math classroom instructors (Grades 3 -12). Based upon future funding, follow-up (Part 2) workshops and additional initial (Part 1) workshops could be set around the state.

Work Plan: Our work plan involved an eight-hour workshop. In those eight hours, we focused on the concept of spaceflight via a variety of hands-on activities (labs, simulations, computations, etc.) and discussions. High emphasis was placed on cooperative work and constructivistic approaches being fueled through facilitator lead Socratic dialogue. The goal was to allow the instructors to have the chance to infuse their new knowledge into their respective curriculums with the hopes that a follow-up workshop can be funded in order to further our focus. 
General Information: Spaceflight Fundamentals, LLC is a small but dedicated company to the advancement of aerospace in the classroom. For the past eleven years, our company has been authoring and publishing educational materials on aerospace education in the state of Wisconsin. Also, in those eleven years, we have had the opportunity to organize and instruct several teacher graduate course workshops. The workshops have always been well received and have made definite positive impacts in our state's classrooms. With that said, our hope is that workshops like these will allow further opportunities to educate and motivate the current and next generation of instructors/students on aerospace education in the state of Wisconsin. We look forward to creating future proposals / activities for teacher aerospace workshops and further broadening our ability to work with other state organizations with the same goals. Based on feedback from our workshop, we know that teachers and students have benefited from our activities. It is our hope to continue being a positive force in the WSGC's community outreach efforts while helping to nurture and grow the aerospace industry in the State of Wisconsin. 